\title{
Recycled Sustainable 3D Printing Materials for Marine Environments
}

\author{
Kate Dunn ${ }^{1}$, M. Hank Haeusler ${ }^{2}$, Yannis Zavoleas ${ }^{3}$, Mel Bishop ${ }^{4}$, \\ Katherine Dafforn ${ }^{5}$, Francisco Sedano ${ }^{6}$, Daniel Yu ${ }^{7}$, Nina Schaefer ${ }^{8}$ \\ ${ }^{1} U N S W^{2} U N S W /$ Computational Design \& CAFA Visual Innovation Institute Bei- \\ jing ${ }^{3}$ UNSW / Computational Design ${ }^{4,5}$ Macquarie University / Biological Science \\ ${ }^{6}$ University of Seville ${ }^{7}$ UNSW / Computational Design ${ }^{8}$ UNSW \\ 1,2,3,7,8 $\left\{\right.$ k.dunn|m.haeusler|y.zavoleas $\mid$ d.yu|n.schaefer\}@unsw.edu.au ${ }^{4,5}$ \{melanie. \\ bishop|katherine.dafforn\}@mq.edu.aursedano@us.ed
}

The paper discusses the design and testing of sustainable recycled materials for large scale $3 D$ printed construction in a marine context. This research is part of a 3-phase project involving a multidisciplinary team of designers, architects, material specialists and marine ecologists. The Bio Shelters Project uses an innovative approach to designing and fabricating marine bio-shelters that ecologically enhance seawalls, by promoting native biodiversity and providing seawater filtration, carbon sequestration and fisheries productivity. The design of the $3 D$ print structure is a data-driven approach that incorporates ecological data to optimise the form for growth and survivorship of marine species under the environmental conditions of the installation site as well as being an integral part of the design project and the site.

Keywords: $3 D$ printing, material research, sustainability, marine biology

\section{BACKGROUND AND MOTIVATION Background}

The 3D print materials and processes developed in this project build on research into robotically controlled extrusion 3D printing using a base material with a range of sustainable additives including clay, sugar, cellulose fibre, recycled paper, wood and waste polystyrene as well as traditional materials such as concrete and gypsum (Dunn et al. 2016). Previous research undertaken in the area of innovative sustainable materials for $3 D$ printing include Utela (2008) whose research approaches 3D printing from an engineering framework focused on ma- terials investigations including sugar, salt, clay and different binders. Emerging Objects lead by Ronald Rael and Virginia Fratello [1] have experimented with salt, sand, tea, sugar, clay and plastics. Their focus is on sustainability and materials development as well as potential uses in architecture. Other precedents include Shelter by El Studio founded by Erno Langenberg [2]. Another important precedent is the research conducted by Gardiner and Dini in reef structures conducted in 2011(Gardiner 2011). This research is particularly relevant to this project as it demonstrates radically innovative and experimental approaches to combining materials for 3D printing and then applying them in different marine contexts. 


\section{Motivation}

The motivation is driven by the needs of the commissioning body and by the specific ecological context of the research project. Bio-shelters is a funded research project through the Co/Lab Grant funding scheme sponsored by LandCom / UrbanGrowth NSW Australia. The 2018 awarded project entitled “Designing Bio-Shelters - Improving water quality and biodiversity in the Bays Precinct through designing novel bio-shelters using dynamic data-driven approaches" aimed to apply advanced computational methods utilised by architects to design green coastal infrastructure. The project was founded on the premise that advanced computational methods used in architecture could also be applied to the design of habitats on seawalls to support ecologically important species. The project aimed to enhance the abundances of native habitat-forming organisms, which are often missing or found in low abundances on seawalls. The design context for the research is the new Sydney Fish Market designed 3XN Architects with collaborators GXN, BVN, Aspect Studios and WallnerWeiss [3] to be completed in 2023 and delivered by UrbanGrowth NSW Development Corporation.

\section{Challenge}

The research challenge of the larger project is to integrate data-driven parametric approaches and building material design to generate site-specific and ecologically specific structures for marine habitats. Out of this context, various challenges such as data-driven design, fabrication using digital and/or robotic tools and material considerations arise.

\section{RESEARCH CONTEXT}

This paper focuses on presenting and discussing the design of a sustainable material for marine habitats in the Bio-Shelters Project. In order to contextualise this research, the following section briefly describes the aspects of the Bio-Shelters completed up to this point. Two main bodies of work have been published and presented since: one on data-driven design (Zav- oleas \& Haeusler 2016) and the second on early proof of concept (Trilsbeck et al. 2019). The discussion presented in this paper builds on both.

\section{Data-driven Design}

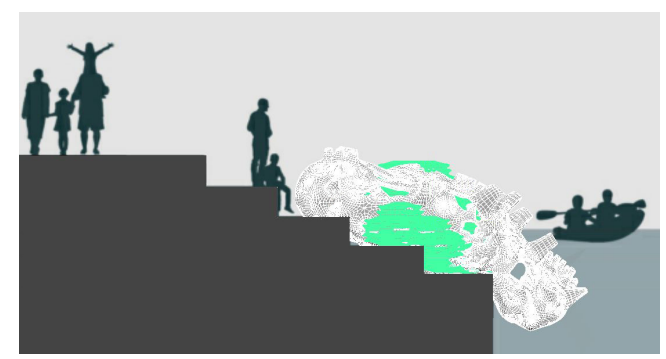

The design parameters for the development of the $3 \mathrm{D}$ print materials used in this project focus on using materials that are fit for purpose, so that they will attract and support the colonisation of desirable native marine species onto marine structures such as seawalls and that are environmentally sustainable. To achieve environmental sustainability, materials will have low toxicity, incorporate waste material and have a minimum production of waste in manufacture. The particular work is part of a research project to produce data-driven design schemes by a performative process. Extensive data inputs and recursive processes are the main applications of computation supporting form-finding techniques (Hensel \& Menges 1991). This project employs data-driven parametric approaches to break down a design problem to multiple agents set by their properties then interacting in dynamic manners to test ideas from initial schemes until final resolution. Even though such an approach generally refers to architectural contexts, this project investigates its applicability to cross-disciplinary design challenges for problems other than conventional architectural ones which concern the broader environment, artificial and natural alike (Zavoleas \& Haeusler 2016) (See Figure 1: Full data-driven design: reef prototype, early testing and site-specific model and Figure 2: Data-driven Design concept developed for project). Earlier phases em-
Figure 1

Full data-driven design: reef prototype, early testing and site-specific model 
Figure 2

Data-driven Design concept developed for the project.
Figure 3

3D printed model in PLA as prototype

Figure 4

Model series of 3D

printing as

conducted in

Trilsbeck et al. 2019
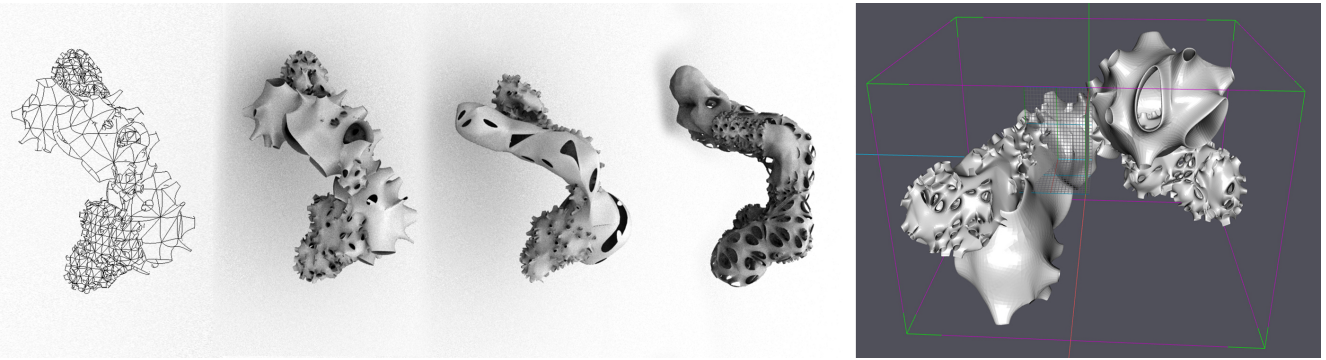

phasised on the analysis of ecological data about reef colonies,
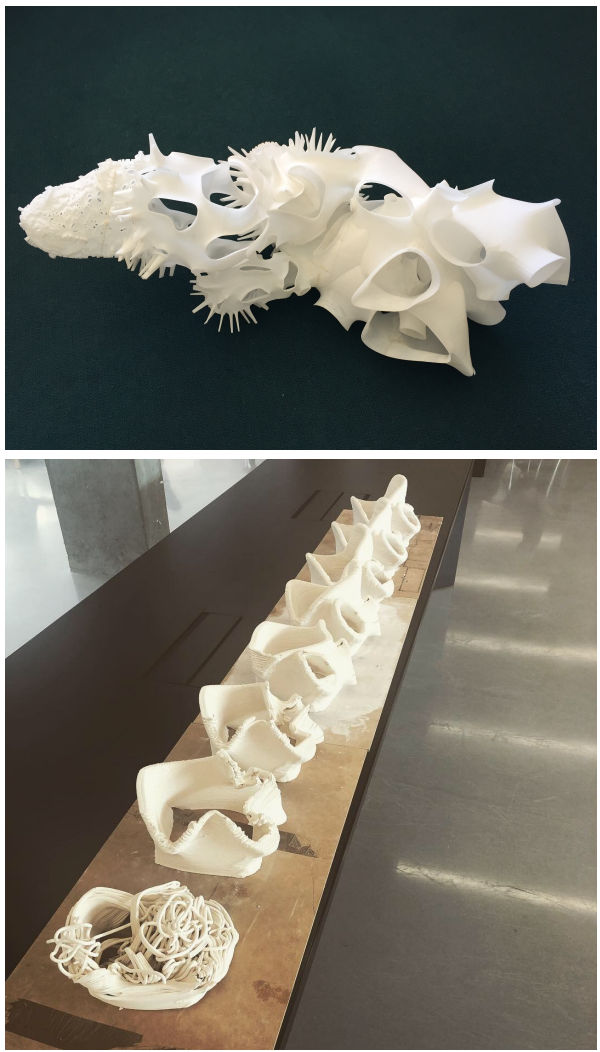

also their processes of formation and interaction with their environment. The proposed schemes demonstrate remarkable complexity and sophistication in shape, structure, behaviour, materiality, fabrication and on-site adaptation.

\section{Early proof of concept}

The first design experiments were drawn from ecological data on marine species, along with sitespecific information related to different site topography and climate. They were designed digitally, then prototyped in miniature size with PLA filaments by using 3D printing techniques. Subsequently, one of the models was scaled up and printed using a Z-corp dimension printer and $A B S$ material. From these early experiments, it was clear that a high level of complexity was attainable (See Figure 3: 3D printed model in PLA as a prototype).

Moreover, the standards of what to expect were set during fabrication at full size, also with more compatible materials sought for the next phase. This second set of testings involved printing larger three-dimensional forms out of physical clay (Trilsbeck et al. 2019). Even though clay shows resilient behaviour and is well-suited to artificial reef and habitat-enhancing seawall structures, its response to highly complex forms is somewhat unpredictable. Consequently, another set of tests was focusing to improve the translation of complex geometries into clay artefacts through additive printing processes, by drawing on the notion of digital craft and by taking advantage of human-machine interaction as a 
collaborative practice, further suggesting hybrid digital/analogue craft perspectives to fabrication (See Figure 4: Model series of 3D printing as conducted in Trilsbeck et al. 2019). These attempts set the first level of familiarity with the endeavours associated with this project, as they were would be pursued in more detail across design script development, data integration, material incorporation and fabrication techniques setting the project's next challenges.

\section{DESIGNING THE MATERIAL}

The approach to the material design of this project in this current phase is based on the same principle as commercially available sustainable filament products including recycled wood filaments, recycled brick filaments and, recently, algal filament. These products rely on a certain percentage of basebonding material such as ABS plastic or PLA to ensure fabrication stability during printing as the base materials melt at a consistent temperature, ensuring consistent bonding of each subsequent layer. The principle of having a base material with different additives has informed the material investigations undertaken in this project. To test a base material of concrete, different materials are subtracted and added to achieve sustainable, functional and aesthetic outcomes. Subtracted materials included sand and crushed rock from traditional concrete mixes. Additive substitute materials included vermiculite (as aggregate and texture variation) iron oxide as a colourant for the concrete and locally-sourced waste biomaterials in the form of crushed oyster shells as aggregate. The inclusion of oyster shells is an important means for achieving not only function but also sustainable material sourcing. The project uses crushed discarded oyster shells sourced from the Sydney fish markets as part of the build material for the bio-shelters that will be installed at the same site.

The marine bio-shelters will be attached to seawalls in order to increase their ecological value. Estuaries in Australia, the United States and Europe have had more than $50 \%$ of their natural coastline modified with artificial structures, such as seawalls, which support low biodiversity and few ecosystem services as compared to the natural habitats they replace. Multifunctional structures are needed that not only serve their intended engineering purpose (e.g. for seawalls, the stabilisation of reclaimed land, and the protection of coastal infrastructure from inundation) but also serve secondary purposes such as the enhancement of fisheries productivity or the maintenance of clean water, by promoting filter-feeders (Dafforn et al. 2015). Oysters are critical to marine ecosystems, helping to maintain clean water by filtering up to 100 litres of water a day, serving as a food resource for fish and providing complex habitat for other invertebrate species [4].

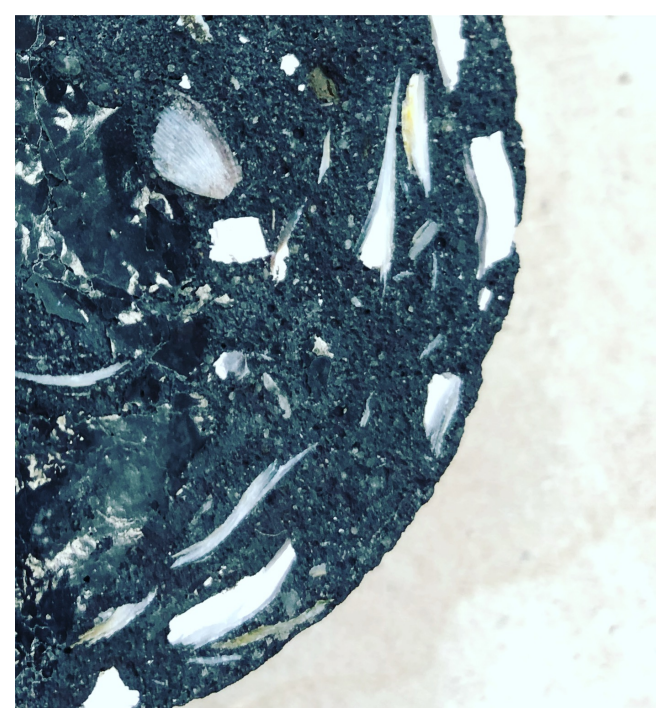

Along the east coast of Australia over $90 \%$ of oyster reefs have been lost, primarily due to historic overharvesting. Oysters colonise by building on other oyster shells. By including oyster shell into the build material of marine development, it encourages oyster colonisation onto structures and rebuilds and rehabilitates an important marine ecosystem. Oysters are in high demand for consumption, with the oyster shell generally disposed in landfill. By using the
Figure 5

Material Tests with reclaimed oyster shell as aggregate, detailed view 
Figure 6

Material Tests with reclaimed oyster shell as aggregate, as part of an art project to test material. waste shells in the build material, the project not only reduces the cost of the build material, but it also reduces landfill. Other projects are incorporating oyster shells in building materials and marine structures include tabby cement, a vernacular building technique from the southern US imported from Spain in the 17th Century (Sheehan 2002), and artificial reefs such as the U.S. Fish and Wildlife Service Project PORTS [5]; the shellfish restoration project in Port Phillip Bay Australia [6]; the artificial oyster reef in Moreton Bay in Queensland, Australia and the San Francisco Bay Oyster Restoration Plan [7].

However, none of the precedents described above use the oyster shells as a component in a 3D print material. The 3D print fabrication process is particularly important to achieve the complex geometries required for colonisation of marine species.

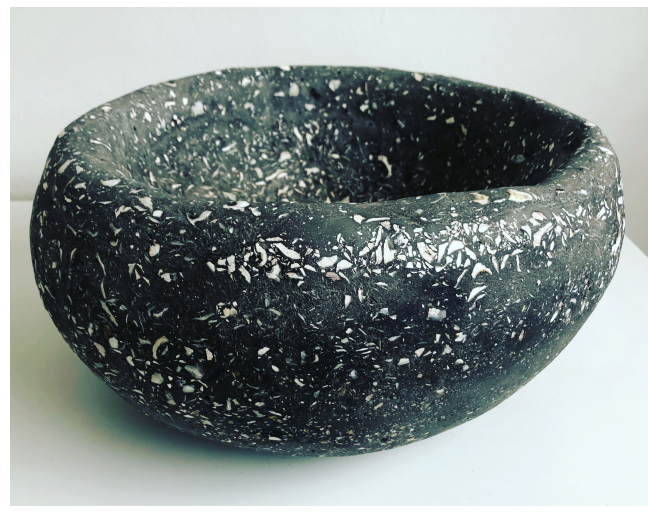

The precedents discussed use fabrication processes such as placing oyster shells in coconut fibre bags at the reef at Moreton Bay, whole oyster shells in plastic nets at the U.S. Fish and Wildlife Service Project PORTS and whole oyster shells mixed with granite at the Port Phillip Bay project. The 3D printed bioshelters will be a structural and functional means of rehabilitating the water and they are also an aesthetically pleasing design feature of the development as they are highly visible at both high and low tide.

\section{EVIDENCE OF FEASIBILITY OF 3D PRINT- ING WITH OYSTER SHELL CONCRETE Printing tests also with designed material}

The 3D printing process used in final stage of the project will be Free Form Fabrication, or Fused Deposition Modelling (FFF/FDM). The process relies on extruding a material through a hose and nozzle in a pattern determined by the $\mathrm{G}$ code developed through the computational design process. The material is extruded and builds up in fine layers supported in places by a scaffold made of either the same material or another that can be dissolved after the printing is complete. This printing process relies on the material bonding with the layer beneath as it is printed to ensure the structural integrity of the final printed object. FFF/FDM printing is relatively easy to adjust for different purposes as some printers are designed for use with different types of filaments and many of the mechanisms can be easily hacked or altered. It is also a process that can be scaled up by introducing large gantry frames and robotic arms for delivering materials. There are numerous research projects investigating the potential of 3D printing different materials using this process. Developers of large scale FFF, include DUS Architects [8] from the Netherlands, Win Sun from China (Bogue 2013), Enrico Dini's D-Shape project [9]. Behrokh Khoshnevis' Contour Crafting project [10] and Audrey Rudenko [11] who are all experimenting with large scale FFF using extruded concrete and plastics. James Gardiner with Laing O'Rourke Construction has developed 3D printed wax for the purposes of large-scale concrete casting (Wu et al. 2016).

A significant body of research has been generated by the Material Processes and Systems Group [MaP+S] (Bechthold 2016). Over an eight-year period the $\mathrm{MaP}+\mathrm{S}$ group have investigated numerous industrial and robotic applications of materials including large scale clay 3D printing. These projects include, Objects of Rotation and Woven Clay. The clay deposition technique is undertaken through robotic extrusion by depositing a clay paste. Other examples of large-scale ceramic 3D printing include WASP 3D 
printed Zero-Mile homes and the Pylos Project by Dubor and Giannakopoulos [12]. Pylos Project focused on using soil mixed with clay for 3D printing and depositing using a KUKA robot. FFF printing is a suitable process for investigating different sustainable $3 \mathrm{D}$ printing materials and is used in this project for the material and process experiments.

\section{MATERIAL TESTS \\ Proof of Concept material Tests}

The design variables for the test tiles included material composition, scale of perforations (to test what marine species would colonise on the tiles) texture and structural integrity. The variables were included in these design parameters in order to test not only their structural performance and efficacy when submerged in sea water for long periods but also their ecological performance in encouraging colonisation of native marine species including biofilms, oysters and different fish. One of the guiding principles in the design of the project was to create the structures in as sustainable a means as possible. The scale of the project meant that using the ceramic materials used in the early stages and firing the components to bisque, would be not only prohibitively slow, it would also produce significant greenhouse gases in the firing process. Alternatively, concrete can be produced at scale, has had significant testing in marine conditions, does not need to be fired and can be altered through the addition and subtraction of elements, making it the ideal base material for testing.

\section{Material Composition variables}

The material Composition tests included:

- A standard concrete mix of 2 parts cement: 1 part sand: 2 parts crushed rock aggregate.

- 2 parts cement: 1 part sand: 1 part vermiculite and 1 part crushed rock aggregate.

- 2 parts cement: 1 part sand:1 part sustainablysourced crushed oyster shells: 1 part crushed rock aggregate.
The additive elements were chosen for the following reasons:

Sand and crushed rock are standard ingredients in concrete and sourced from hardware stores.

Vermiculite (hydrated laminar magnesiumaluminum-iron silicate) (Hombostel 1991) was tested as it is a porous very lightweight material used in this context to reduce the weight of the concrete bioshelters, add texture and encourage anchor points for different species to attach to.

Oyster shells were sourced from the Sydney Fish Market vendors and crushed with a Rock Crushing Machine and a Ball Mill located at the UNSW Faculty of Mining Engineering then sieved through a mesh sieve.

\section{Scale of perforations texture and structural integrity}

A series of silicon moulds were produced in order to replicate and standardise the size, shape, form and perforations. Thirty of the tiles had no texture while thirty had the same size perforations (as seen in figure 8).To date, sixty $200 \times 200 \times 50 \mathrm{~mm}$ tiles have been fabricated and are currently in the ocean for testing. The tiles were secured to a steel mesh frame and submerged into the ocean in the intertidal zone at Blackwattle Bay, Sydney to test the structural integrity of the material in marine conditions and more importantly to test how they interact with marine life. These material test components will stay in the ocean for 6 weeks and 6 months and then be evaluated by marine scientists and engineers to test their ecological and structural performance and efficacy.

\section{FUTURE WORK}

With a LandCom / UrbanGrowth NSW as its commercial client, this research project's main goal is set towards producing a proof of concept model that assures the client that it is feasible to build a seawall using the proposed method. Feasible in the sense of the project is to deliver evidence in terms of meeting Australian standards, being compliant to structural and WH\&S regulations, and so to mass produce 
Figure 7

Diagram of material composition of tiles. (Diagram by Francisco Sedano)

Figure 8

Silicon moulds and concrete models
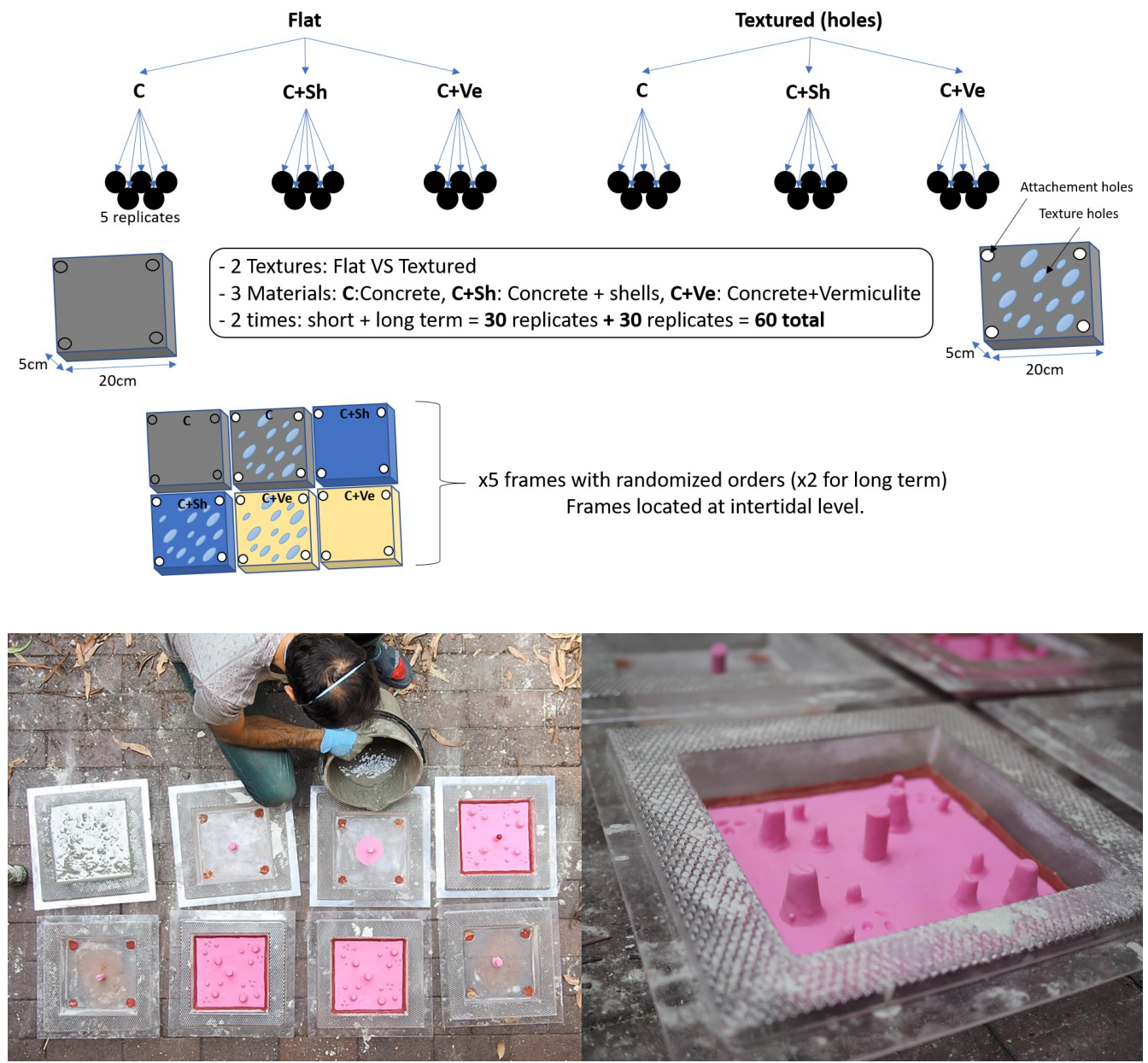


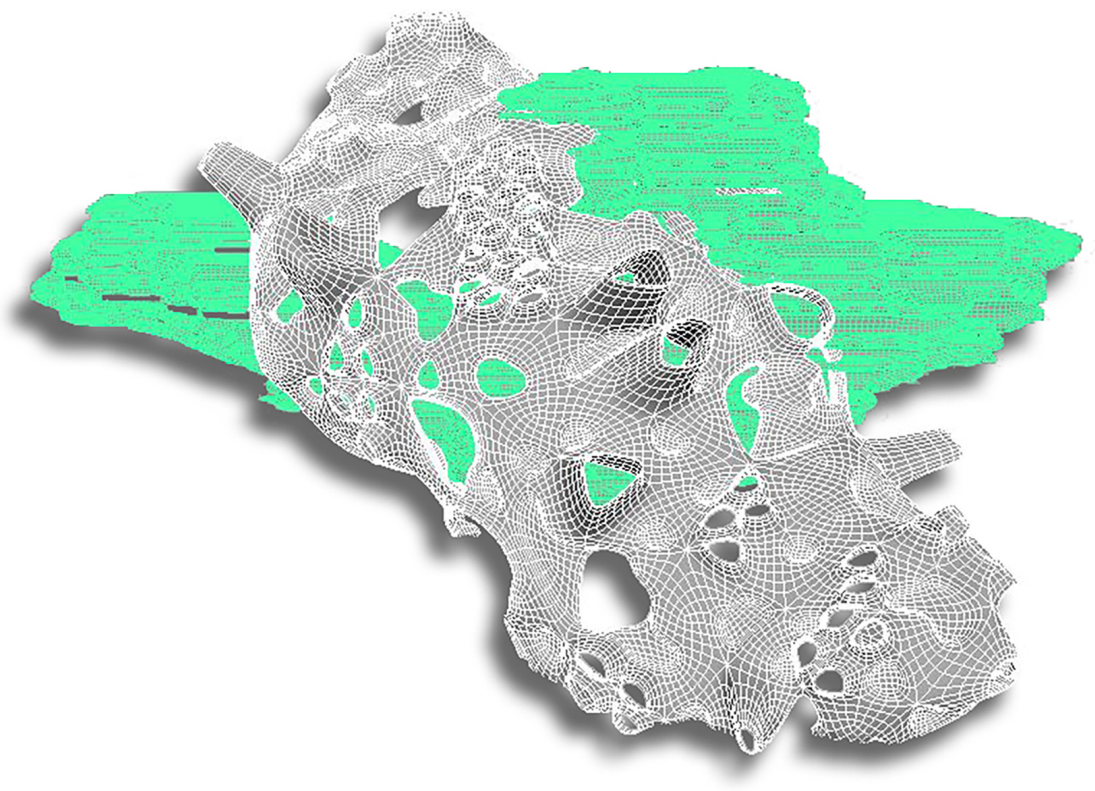

Figure 9

Design file handed over to both firms for feasibility study for printing with their respective technique.

outcome on a commercially viable rate. In short, the client should be able to base one's decision on the fact that the proposed solution meets the same requirements as a standard straight seawall.

In order to meet these requirements the research team started discussions towards large scale fabrication with two companies, Laing O'Rourke Freefab Wax(TM)and XtreeE. Here the production process differs from firm to firm.

\section{Freefab Wax (TM)}

Freefab Wax(TM) (2019) [13] describes themselves as a "construction scale 3D printing technology that allows complex concrete building components and pro- totypes to be designed \& developed more cost effectively and with shorter lead times than current alternatives". Their fabrication process "combines both $3 D$ printing and 5 axis surface milling to deliver a hybrid technology for the fabrication of precision moulds for the construction and other industries" and hence is " ideally suited to off-site precast factory environments, producing moulds for simple to complex precast and GRC products more efficiently than conventional technologies." Of particular interest in the project's sustainable context is that Freefab Wax(TM) uses wax for its moulds. According to their website, this has [23] "significant benefits over conventional mould production, as the wax from moulds is filtered and re-used di- 
rectly, recovering more than $90 \%$ of materials. This results in dramatically less waste, lower embodied energy in each product and reduced material consumption".

\section{XTreeE}

XTreeE is a large scale 3D printing technology company using an adaptive concrete 3D printing technique via a robot arm. While several companies and research institutions research in a similar direction, our choice for XTreeE stems out of their background and experience in 3D printing artificial reefs. In December 2017 XTreeE and SeaBoost (Egis Group) have collaborated on the Rexcor Artificial Reef and according to their XTreeE's website [14] "combined their skills in large-scale 3D-printing and marine biology to design, manufacture and implement one of the most innovative artificial reefs ever built".

\section{Next Steps}

At the time of writing this paper, both companies have been given the 3D model to test and evaluate in order to investigate if their respective fabrication techniques allow the mass fabrication of an artificial seawall while using the following assessment criteria:

- using the material currently being discussed;

- providing overview on the fabrication / machining time, fabrication costs by square meter or cubic meter;

- segmentation of elements for transportation and assembly;

- meeting Australian regulations;

- sustainability of the fabrication process and transportation.

Based on the feedback of both companies the research team needs to potentially alter the design towards manufacturing constraints and via an iterative loop, to balance the data-driven design intent with manufacturing constraints. After completing this iterative process, the time plans are - depending on costs and shipment constraints - to print both as an approximately one square meter 1:1 prototype and then to test the fabricated prototype(s) in situ in the
Sydney Harbour.

\section{ACKNOWLEDGEMENT}

We would like to acknowledge Liane Rossler's collaboration of the design work in Figure 6. Further we would like to acknowledge the help and discussions we had with the Landcom / UrbanGrowth team Michael Parson, Nicole Campbell, Jennifer Chang, Greg Lin, Humphrey Whitaker, Jenny Kline, Joanne Vaughan, and Leo Nelson

\section{REFERENCES}

Bechthold, M 2016, 'Ceramic Prototypes-Design, Computation, and Digital Fabrication', Informes de la Construcción, 68(544), p. 167

Bogue, R 2013, '3D printing: the dawn of a new era in manufacturing?', Assembly Automation, 33(4), pp. 307-311

Dafforn, K A, Glasby, T M, Airoldi, L, M, Mayer-Pinto and Johnston, E L 2015, 'Marine Urbanization: An Ecological Framework for Designing Multifunctional Artificial Structures', The Ecological Society of America Frontiers in Ecology and the Environment, 13(2), pp. 82-90

Dunn, K M, Wozinack O, D and Ulacco, G 2016, 'Free Form Clay Deposition in Custom Generated Moulds', in Reinhardt, D, Saunders, R and Burry, J (eds) 2016, Robotic Fabrication in Architecture, Art and Design, Springer, pp. 317-326

Gardiner, J 2011, Exploring the emerging design territory of construction 3D printing-project led architectural research., Ph.D. Thesis, RMIT University Melbourne Australia

Hensel, M and Menges, A 2007, Morpho-Ecologies, Architectural Association, London

Hombostel, C 1991, Construction Materials: Types, Uses, and Applications, John Wiley \& Sons, Inc $\backslash$, New York

Sheehan, M S and Sickels-Taves, L B 2002, 'Venacular building materials and the factors conditioning their use: tabby a case study.', Material Culture, 34(2), pp. 16-28

Trilsbeck, M, Gardner, N, Haeusler, M H, Zavoleas, Y and Page, M 2019, 'Meeting in the middle: Hybrid clay three-dimensional fabrication processes for bio-reef structures', International Journal of Architectural Computing, 00(1-18), p. (0)

Utela, B, Storti, D, Anderson, R and Ganter, M 2008, 'A review of process development steps for new ma- 
terial systems in three-dimensional printing (3DP), Journal of Manufacturing Processes, 10(2), pp. 96-104 Wu, P, Jun, W and Xiangyu, W 2016, 'A critical review of the use of 3-D printing in the construction industry', Automation in Construction, 68, pp. 21-31

Zavoleas, Y and Haeusler, M H 2017 'Extended modelling - Dynamic approaches applied to design reef habitats at Sydney Harbour', ShoCK! - Sharing Computational Knowledge! - Proceedings of the 35th eCAADe Conference, Rome, pp. 67-74

[1] https://www.emergingobjects.com/

[2] http://www.3dprintingarchitecture.net/?p=521

[3] https://3xn.com/project/sydney-fish-market

[4] https://www.sbs.com.au/news/how-old-oyster-shell s-are-reviving-a-queensland-reef

[5] https://usfwsnortheast.wordpress.com/2015/05/22/ shells-and-students-in-southern-new-jersey/

[6] https://vfa.vic.gov.au/recreational-fishing/recreatio nal-fishing-reefs/shellfish-reefs

[7] https://baynature.org/article/artificial-reefs-for-oyst ers/

[8] https://d-shape.com/what-is-it/the-process/

[9] https://houseofdus.com/

[10] http://contourcrafting.com

[11] https://iaac.net/research-projects/large-scale-3d-p rinting/pylos/

[12] http://www.totalkustom.com/

[13] https://www.freefab.com/

[14] http://www.xtreee.eu/project-rexcor-artificial-reef 